\title{
Dissolution Kinetics and PAG Interaction of Phenolic Resins in Chemically Amplified Resists
}

\author{
Hiroshi Ito, Debra-Fenzel Alexander, and Greg Breyta \\ IBM Almaden Research Center, 650 Harry Road, San Jose, CA 95120, U.S.A.
}

\begin{abstract}
This paper describes the dissolution behavior of phenolic resins and resists in aqueous base solutions as measured with a quartz crystal microbalance. The dissolution kinetics of poly(4-hydroxystyrene) is linear with time, irrespective of molecular weights and polydispersities (including tandem blends). The effects of the composition of poly(4hydroxystyrene-co-t-butyl acrylate) (ESCAP resin) and the loading of triphenylsulfonium triflate on the dissolution kinetics have been studied, revealing that the dissolution rate exponentially decreases with increasing the acrylate and triflate contents. A longer induction period is observed at a higher acrylate and triflate concentration. The dissolution inhibition effect of acid generators has been correlated with an interaction between the phenolic $\mathrm{OH}$ group and an acid generator molecule as studied by ${ }^{13} \mathrm{C}$ NMR. The strong interaction of onium salts with phenol is clearly observed also in IR spectra of the above copolymer films. The quartz crystal microbalance has provided valuable information on the dissolution kinetics of exposed Shipley UVIIHS resist films, which exhibit a very fast dissolution of $30,000 \AA / \mathrm{sec}$. The dissolution rates of the exposed resist films have been correlated with the degrees of deprotection as determined by thickness measurements, $\mathbb{R}$, and ${ }^{13} \mathrm{C}$ NMR, and also with the rate values of authentic terpolymers of 4-hydroxystyrene, $t$-butyl acrylate, and acrylic acid, which had been prepared from an ESCAP copolymer.

Keywords: quartz crystal microbalance, chemical amplification, dissolution kinetics, acid-catalyzed deprotection
\end{abstract}

\section{Introduction}

In both $\mathrm{i}$-line and deep UV lithographies aqueous base development plays a key role in generating high resolution images with vertical wall profiles; high performance resists convert the sinusoidal aerial image to a step function during the aqueous development process. The systematic studies on the effect of the novolac resin structure on their interactions with photoactive diazonaphthoquinone dissolution inhibitors and their dissolution behavior in aqueous base have resulted in enhancement of their performance to < $300 \mathrm{~nm}$ resolution. The new deep UV imaging technology based on the use of chemically amplified resists must comply with the rules established with the diazoquinone/novolac resists to be accepted in device manufacture. One of such important requirements is compatibility with a 0.26
$\mathrm{N}$ tetramethylammonium hydroxide (TMAH) developer, while poly(4-hydroxystyrene) (PHOST) on which deep UV resists are exclusively built dissolves much faster than novolac resins in aqueous base. Furthermore, the acid-catalyzed imaging mechanism provides such high contrasts that it is more difficult to monitor the dissolution behavior of the deep UV positive resists. Thus, while the dissolution measurements of chemically-amplified resists by laser interferometry have been less successful, an alternative methodology employing a quartz crystal microbalance (QCM) has been extensively utilized at IBM Almaden Research Center in investigation of the dissolution kinetics of phenolic resists [1-3]. The QCM technique can be readily applied to measurements of extremely 
fast dissolution rates and to investigation of a detailed dissolution behavior in a very short time scale.

This paper reports the dissolution kinetics of PHOST with a wide range of molecular weights $\left(M_{n}=2,300-26,000\right)$ and molecular weight distributions $\quad\left(\mathrm{M}_{\mathrm{w}} / \mathrm{M}_{\mathrm{n}}=1.2-5.5\right), \quad$ poly(4hydroxystyrene-co- $t$-butyl acrylate) $\{\mathrm{P}(\mathrm{HOST}-c o-$ TBA)\} with the TBA concentration ranging from 30 to $40 \%$, and the copolymer films containing a varying amount of triphenylsulfonium trifluoromethanesulfonate (TPSOTf). The dissolution inhibition effect of onium salt acid generators has been investigated in terms of their interaction with the phenolic $\mathrm{OH}$ group by ${ }^{13} \mathrm{C}$ NMR. In addition, the dissolution behavior of the Shipley UVIIHS resist [4], built on IBM's ESCAP platform [5], is described in detail.

\section{Experimental}

\subsection{Materials}

PHOSTs which had been previously described [6] were subjected to QCM dissolution measurements; Hoechst-Celanese products prepared by conventional radical polymerization, narrow polydispersity $\left(P D=M_{w} / M_{n}\right)$ polymers prepared by living radical polymerization of 4acetoxystyrene with a TEMPO adduct [7] and subsequent base hydrolysis, and several mixtures of narrow PD polymers including blends with tandem molecular weight distributions.

The synthesis of P(HOST-co-TBA) has been previously reported [5]. The UVIIHS resist employed in this study was an in-house formulation. Authentic terpolymers of HOST, TBA and, acrylic acid (AA), \{P(HOST-TBA-AA) $\}$, were prepared by treating $\mathrm{P}(\mathrm{HOST}-\mathrm{co}$-TBA) $(\mathrm{HOST} / \mathrm{TBA}=61.5 / 38.5)$ with $\mathrm{HCl}$ in dioxane at 70 ${ }^{\circ} \mathrm{C}$.

The casting solvent was ethyl lactate in all the cases. MF321 $(0.21 \mathrm{~N})$ and CD-26 $(0.26 \mathrm{~N})$ were used as aqueous TMAH developers.

\subsection{Dissolution Measurements on QCM}

The quartz crystals employed in this study had an inherent frequency of about $5 \mathrm{MHz}$. Quartz crystal discs with gold contacts were coated with phenolic polymer films, baked at $130-150^{\circ} \mathrm{C}$ for 60 sec, and mounted on a sensor probe. A Maxtek TPS-550 sensor probe and PI-70 driver were used in conjunction with a Phillips PM6654 programmable high resolution frequency counter and an IBM PC. The instrumentation was controlled and data were collected by a custommade LabView software program. The upper limit of the data density was 200 points $/ \mathrm{sec}$, which allowed us to follow extremely fast dissolution reliably.

2.3. ${ }^{13} \mathrm{C}$ NMR Studies on Interaction between Phenol and Acid Generator

4-Isopropylphenol, a model compound of PHOST, and a photochemical acid generator (PAG) were dissolved in $\mathrm{CDCl}_{3}$ and subjected to $62.9 \mathrm{MHz}{ }^{13} \mathrm{C} \mathrm{NMR}$ at room temperatures. The concentration of acid generators was kept constant relative to the phenolic compound on the molar basis. The chemical shifts of the aromatic carbons in the phenolic model compound were compared in the presence and absence of acid generators.

2.4. Measurements of Contrasts, IR, ${ }^{13} \mathrm{C}$ NMR, and QCM of UVIIHS ESCAP

An Optical Associate Inc. deep UV exposure station and an 8" cut-off filter were used for consistency in all the exposures of UVIIHS to generate contrast curves, to monitor the deprotection reaction by thickness measurements, FT-IR, and ${ }^{13} \mathrm{C}$ NMR, and to measure dissolution rates on QCM. IR spectra were obtained on a Nicolet 510 FT-IR spectrometer. Film thickness was measured using a Nanometrics Nanospec AFT4150. To obtain quantitative data on the level of the acid-catalyzed deprotection as a function of the exposure dose, inverse gate ${ }^{13} \mathrm{C}$ NMR with a minimum nuclear Overhauser effect was utilized in conjunction with the use of $\mathrm{Cr}(\mathrm{acac})_{3}$ as a spin relaxation agent. Since a good signal-to-noise ratio was critical to these NMR studies, fifteen 5" silicon wafers were coated with UVIIHS to $\sim 1-\mu \mathrm{m}$-thickness and exposed to a specified dose and the exposed/postbaked resist films were scraped off to provide $80-100 \mathrm{mg}$ of powder for each NMR measurement, which was dissolved in acetone- $\mathrm{d}_{6}$ along with $10 \mathrm{wt} \%$ (to the polymer) of $\mathrm{Cr}(\mathrm{acac})_{3}$. The number of scan employed was 30,000 on a Bruker AF250 spectrometer.

\section{Results and Discussion}

\subsection{Poly(4-hydroxystyrene)}


Because PHOST is the material on which almost all the advanced deep UV positive and negative resists are built, it is important to study its dissolution kinetics systematically as a function of molecular weight, polydispersity $\left(P D=M_{w} / M_{n}\right)$, etc. It has been previously shown [6] that the dissolution rate of PHOST decreases exponentially with an increase in molecular weight and is controlled by $M_{n}$ independent of $M_{w}$ (or PD). This observation suggests that a lower molecular weight fraction does not dissolve away in an earlier stage. Since the dissolution rates reported in the paper [6] were time-averaged values, we have examined the dissolution of the PHOST films by QCM to see whether or not the kinetics is linear with time. Spin-cast films were baked at $150^{\circ} \mathrm{C}$ for $60 \mathrm{sec}$ to minimize the residual casting solvent and then immersed in MF321 (0.21 N TMAH). Figure 1 exhibits dissolution kinetics curves of PHOSTs with $\mathrm{M}_{\mathrm{n}}=2,300-26,000$ and $\mathrm{PD}=1.2$ (narrow)-5.5 (tandem blend). The dissolution is highly linear with time irrespective of $M_{n}$ or PD. Thus, the average dissolution rates determined from the slopes of Fig. 1 agree completely with the values previously obtained manually by measuring time for complete dissolution [6]. Even blends with tandem molecular weight distributions dissolve at constant rates.

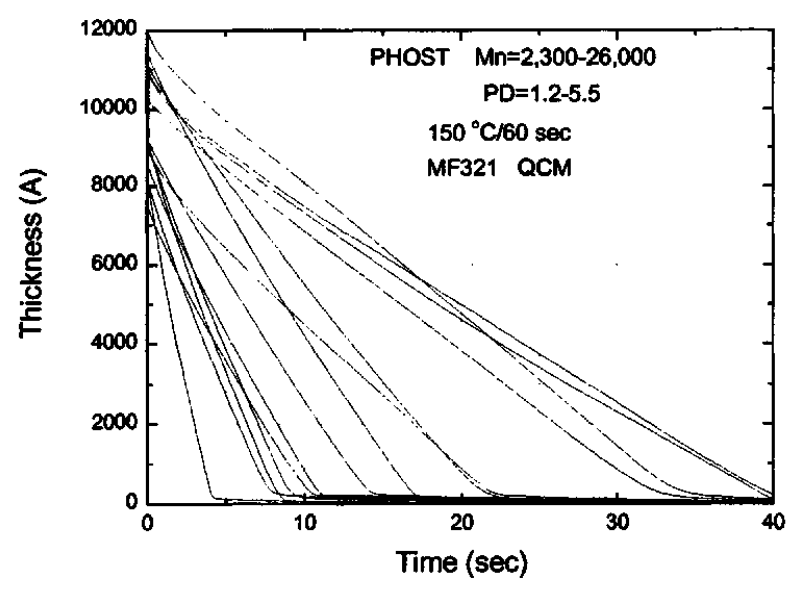

Fig. 1. Dissolution kinetics of PHOST films $\left(M_{n}=2,300-26,000, P D=1.2-5.5\right)$ in $M F 321$.

Some of the PHOST films (living radical polymers; $M_{n}=7,600,12,900,26,000$ : conventional radical polymer; $M_{n}=9,100$ ) were subjected to atomic force microscopy (AFM) analysis after baking and after dipping briefly in MF321 to examine the surface roughness. The surface mapping presented in Figure 2 indicates that the baked films have a smooth surface with the mean roughness of 1-2 $\AA$ and that the aqueous base treatment induces some but small surface roughness (mean roughness of 9-10 $\AA$ ). The mean roughness of the film surface before and after aqueous base treatment does not seem to be a function of molecular weight or PD of PHOST.

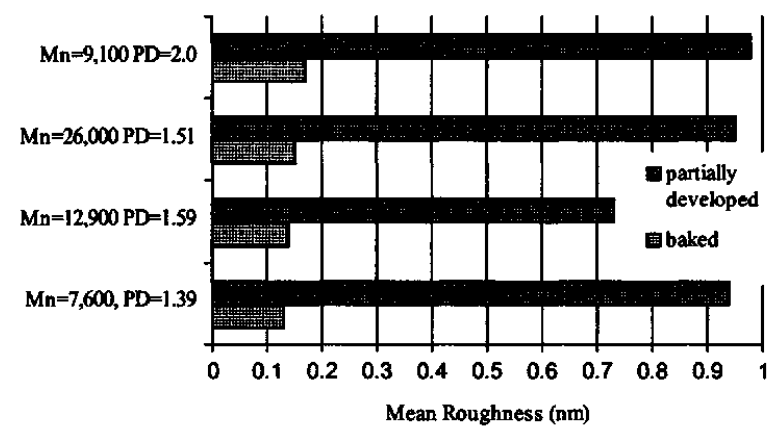

Fig. 2. Mean roughness of PHOST films before and after aqueous base treatment as measured by AFM.

\section{2. $\mathrm{P}(\mathrm{HOST}-c o$-TBA)}

$\mathrm{P}(\mathrm{HOST}-\mathrm{co}-\mathrm{TBA})$ is the major ingredient of the ESCAP and Shipley's UVIIHS/UVIII resists. The influence of the composition of the copolymer on its dissolution rate was studied in a $0.26 \mathrm{~N}$ TMAH developer (CD-26) using QCM. The composition, molecular weights, and glass transition temperature $\left(\mathrm{T}_{\mathrm{g}}\right)$ of the copolymers employed in this study are tabulated in Table I. Attempts were made to keep the molecular weight variation minimal.

Table 1 P(HOST-co-TBA)s
\begin{tabular}{|c|c|c|c|c|}
\hline HOST/TBA & $\mathrm{M}_{\mathrm{w}}$ & $\mathrm{M}_{n}$ & $\mathrm{PD}$ & $\Upsilon_{\mathrm{q}}\left({ }^{\circ} \mathrm{C}\right)$ \\
\hline $60 / 40$ & 33,800 & 20,200 & 1.7 & 150 \\
\hline $65 / 35$ & 29,800 & 17,600 & 1.7 & 153 \\
\hline $67.5 / 32.5$ & 25,600 & 11,200 & 2.3 & 154 \\
\hline $70 / 30$ & 27,000 & 14,400 & 1.9 & 158 \\
\hline
\end{tabular}

The average dissolution rates of $\mathrm{P}$ (HOST$c o$-TBA) in a $0.26 \mathrm{~N}$ TMAH solution as a function of the copolymer composition are presented in Figure 3 for two different bake temperatures, 130 and $150{ }^{\circ} \mathrm{C}$. The lower temperature bake results in a higher dissolution rate due to a larger amount of the residual casting solvent. The dissolution rate becomes exponentially smaller as the TBA concentration in the copolymer increases. The dissolution rate change in CD-26 is insignificant above $35 \%$ TBA. The variation in the molecular weight may be responsible for the small scatter observed in the plots; the 67.5/32.5 composition seems to give a higher dissolution rate than anticipated for this 
composition, which is probably due to its lower molecular weight.

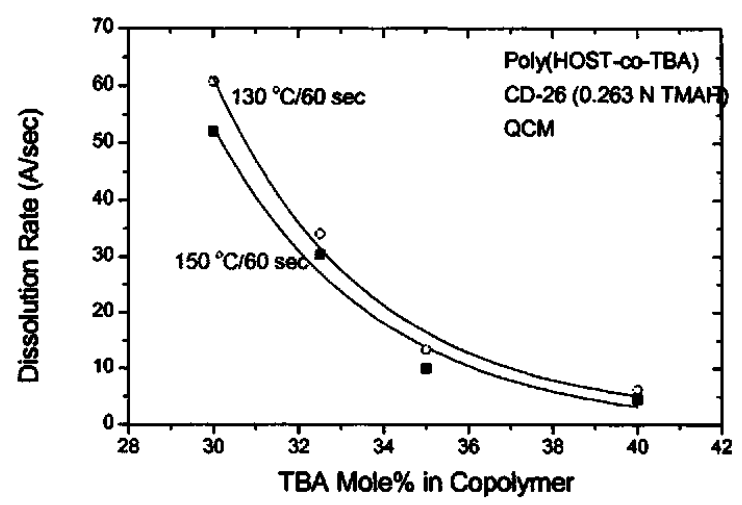

Fig. 3. Dissolution rates of $P(H O S T-c o-T B A)$ in CD-26 as a function of copolymer composition.

3.3. Interaction between Acid Generator and Phenol: Dissolution Inhibition

Certain onium salt acid generators have been reported to be excellent dissolution inhibitors of phenolic resins [2,8]. For the dissolution inhibition to take place, an acid generator must interact with a phenolic group. We examined the interaction by ${ }^{13} \mathrm{C}$ NMR, employing 4isopropylphenol as a model compound of PHOST, in $\mathrm{CDCl}_{3}$. Figure 4 presents aromatic $\mathrm{Cl}$ and $\mathrm{C} 4$ resonances of 4-isopropylphenol in the presence and absence of di(4-t-butylphenyl)iodonium triflate (DTBPIOTf). It is clearly seen that the acid generator induces a significant shift in the $\mathrm{C} 1$ (13.5 $\mathrm{Hz}$ downfield) and $\mathrm{C} 4(13.3 \mathrm{~Hz}$ upfield) resonances of the phenolic compound. The shifts of other resonances such as aromatic $\mathrm{C} 2$ and $\mathrm{C} 3$ and aliphatic carbons of 4-isopropylphenol are much smaller. In the parallel experiments, we have observed that the ${ }^{13} \mathrm{C}$ chemical shifts of the acid generator are affected by the presence of the phenolic compound.

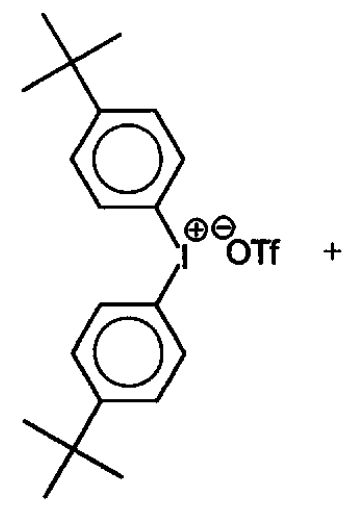

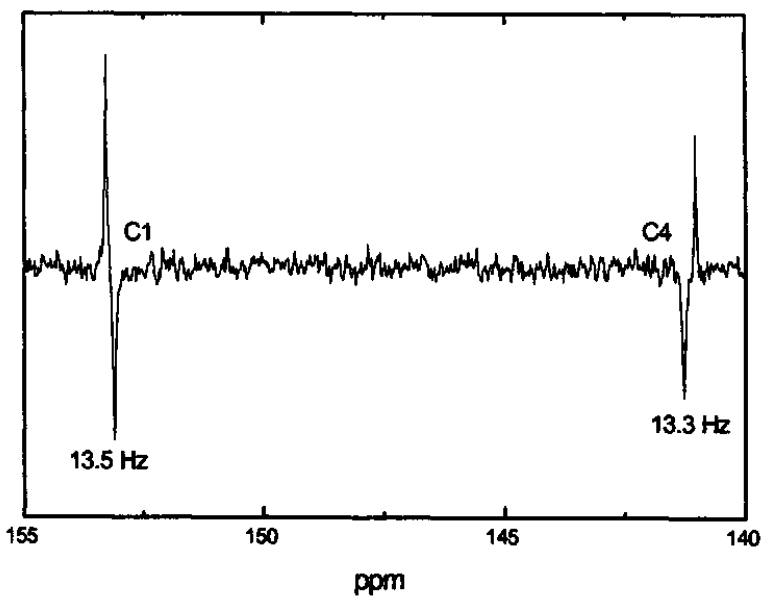

Fig. 4. $62.9 \mathrm{MHz}{ }^{13} \mathrm{C}$ NMR of 4-isopropylphenol in the presence (upward) and absence (downward) of $6.2 \mathrm{~mol} \%$ of DTBPIOTf in $\mathrm{CDCl}_{3}$.

Similar measurements have been carried out with more than twenty acid generators and a so-called dissolution inhibitor, bisphenol A protected with $t \mathrm{BOC}$ (BISBOC), with their concentrations kept constant relative to the phenolic compound on the molar basis (6.2 mol\%). The shifts of $\mathrm{C} 1$ and $\mathrm{C} 4$ induced by 1 mol\% of PAG varied from 0.5 to $10 \mathrm{~Hz}$. Some representative results are presented in Figure 5. BISBOC induced only $0.7-0.8 \mathrm{~Hz} / \mathrm{mol} \%$ shifts, while diphenyliodonium triflate (DPIOTf) and tripheylsulfonium triflate (TPSOTf) interact with the phenol more strongly. Non-ionic acid generators such as $N$-camphorsulfonyloxynaphthalimide (CSN), $N$-trifluoromethanesulfonyloxynaphthalimide (NIT), and 1,2,3(trisethanesulfonyloxy)benzene (Pyro-Et) exhibit a weaker interaction than their ionic counterparts.

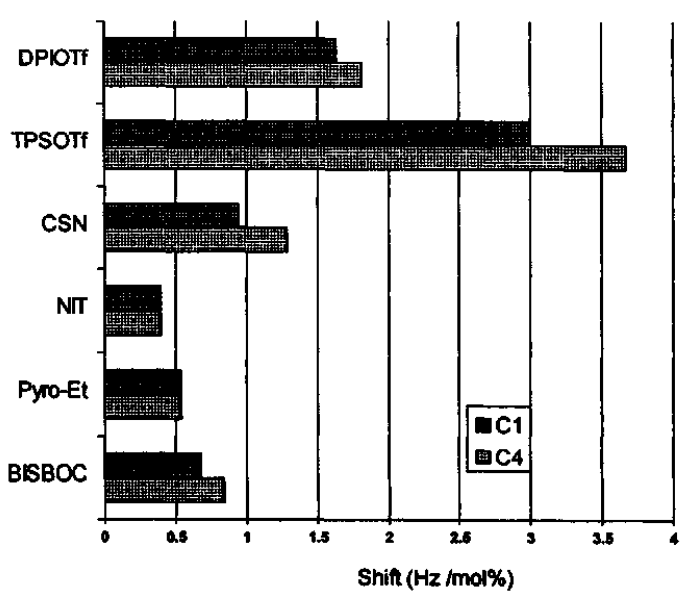

Fig. 5. Shifts of aromatic $\mathrm{Cl}$ and $\mathrm{C} 4$ resonances of 4isopropylphenol induced by additives. 
Figure 6 presents dissolution kinetics curves of $\mathrm{P}\left(\mathrm{HOST}_{0.7}-c o-\mathrm{TBA}_{0.3}\right)$ containing 0.2 mol\% of PAG. The films were baked at $150^{\circ} \mathrm{C}$ for $60 \mathrm{sec}$ prior to dissolution measurements by QCM in CD-26. It is clear that onium salts such as DTBPIOTf and di(t-butylphenyl)iodonium camphorsulfonate (DTBPIOCS) are strong dissolution inhibitors whereas CSN is very much neutral and that the inhibition effect depends on the onium salt structure.

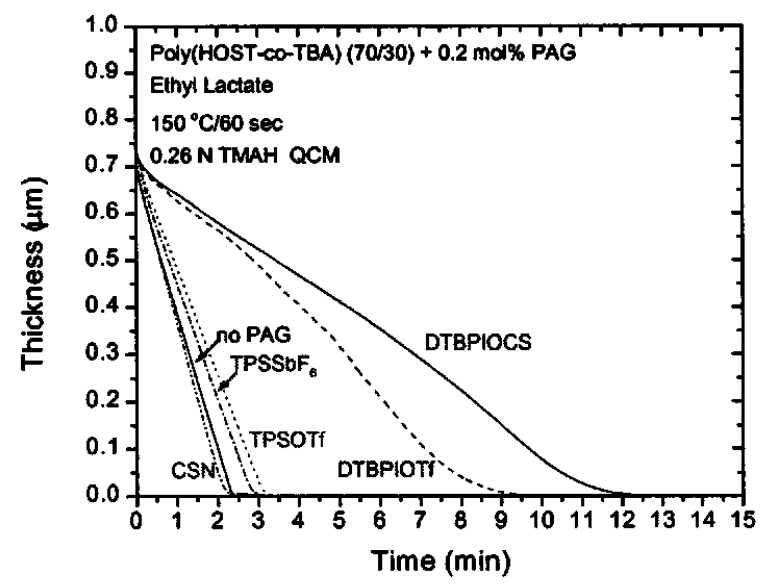

Fig. 6. Dissolution kinetics of $\mathrm{P}(\mathrm{HOST}$-co-TBA) (70/30) containing PAG.

Attempts have been made to correlate the ${ }^{13} \mathrm{C}$ resonance shift with the dissolution inhibition effect of PAG. Figure 7 shows the plots of the dissolution inhibition effect as expressed by the ratio of the dissolution rate in the presence of PAG $(0.2 \mathrm{~mol} \%)$ to the dissolution rate of the pure copolymer film versus the shift of the $\mathrm{C} 4$ resonance of 4-isopropylphenol induced by $1 \mathrm{~mol} \%$ of added PAG. The films for the dissolution measurements in CD-26 were baked at $150{ }^{\circ} \mathrm{C}$ for $60 \mathrm{sec}$. Although there are some scatters in the plot, the dissolution inhibition effect seems to become larger when the PAG induces a larger shift of the C4 (and C1) resonance of the phenolic compound. Fig. 7 indicates that onium salts such as DTBPIOTf, DTBPIOCS, TPSOTf, triphenylsulfonium hexafluoroantimonate $\left(\mathrm{TPSSbF}_{6}\right)$, 4-tolyl(diphenyl)sulfonium triflate $\left(\mathrm{CH}_{3} \mathrm{TPSOT}\right)$, and 4tolyl(diphenyl)sulfoxonium triflate $\left(\mathrm{CH}_{3}\right.$ TPSOOTf) [9] are much stronger dissolution inhibitors than non-ionic PAGs and BISBOC. BISBOC, which is called a "dissolution inhibitor," is very much neutral at such a low concentration.

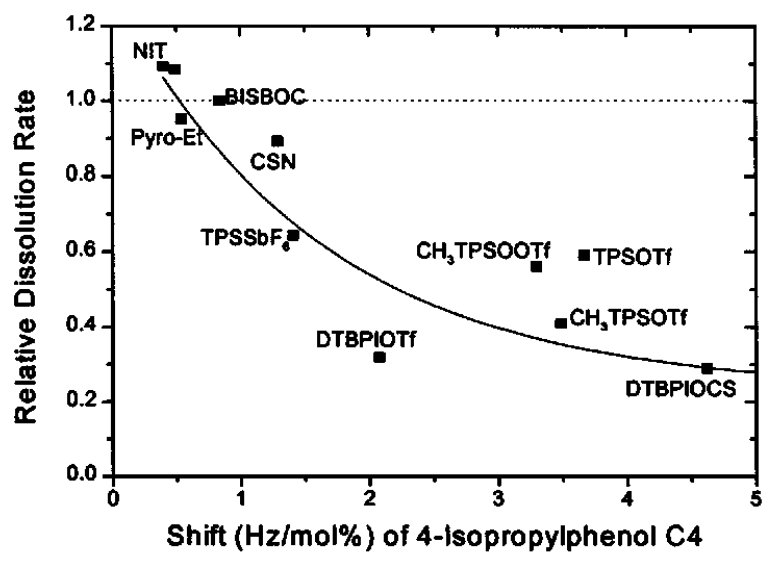

Fig. 7. Relationship between dissolution inhibition effect and shift of 4-isopropylphenol C4 resonance.

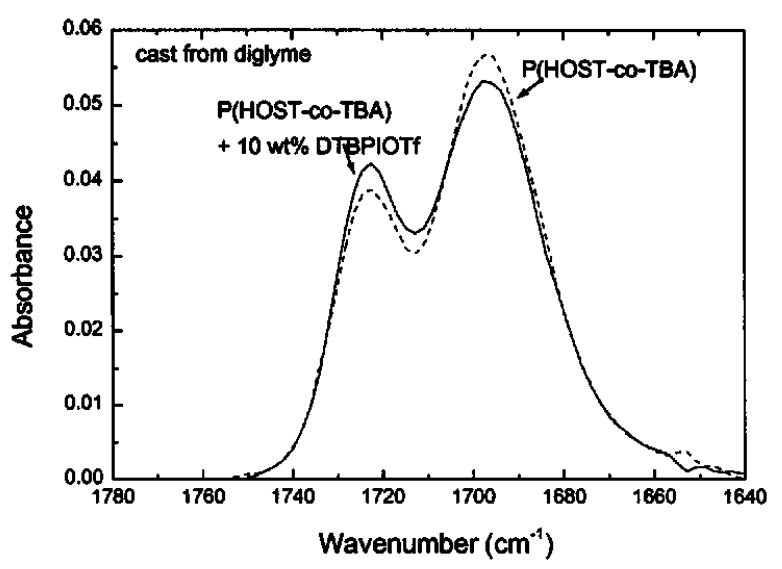

Fig. 8. IR spectra of $\mathrm{P}(\mathrm{HOST}$-co-TBA) films in the presence and absence of DTBPIOTf.

The strong interaction of onium PAGs with a phenolic functionality has been also observed by FT-IR. Figure 8 presents carbonyl IR absorptions of P(HOST-co-TBA) in the presence and absence of DTBPIOTf . The films were cast from diglyme, a solvent which does not have a carbonyl group, and baked at $150^{\circ} \mathrm{C}$ for $60 \mathrm{sec}$. The pure polymer film exhibits two carbonyl absorptions due to a free $\left(1724 \mathrm{~cm}^{-1}\right)$ and hydrogen-bonded $\left(1698 \mathrm{~cm}^{-1}\right)$ ester groups. The ester group of the TBA unit is very much hydrogen-bonded with the phenolic $\mathrm{OH}$ group of the HOST unit in the copolymer film. When DTBPIOTf is added (10 wt\% in this case), however, the ester group becomes less hydrogenbonded, suggesting that the added PAG interacts more strongly with the phenol group than the $t$ butyl ester in the polymer. The influence of added onium PAG can be observed at lower loadings and with other onium salts as well. This 
observation is consistent with our NMR and dissolution studies; BISBOC interacts with phenol and inhibits its dissolution, more weakly than onium salts.

\subsection{Dissolution Behavior of P(HOST-co- TBA)/TPSOTf}

The influence of dissolution inhibiting onium PAGs on the dissolution behavior of the ESCAP copolymers has been investigated, employing TPSOTf as a representative example, on QCM. The TPSOTf loading was varied in a wide range upto about $20 \mathrm{wt} \%$ of the total solid. The polymer films were baked at $150{ }^{\circ} \mathrm{C}$ for $60 \mathrm{sec}$ prior to dissolution measurements in a $0.26 \mathrm{~N}$ TMAH developer (CD-26). The dissolution kinetics of the P(HOST-co-TBA) film as a function of the TPSOTf loading is presented in Figure 9. Addition of TPSOTf results in reduced dissolution rates. While the dissolution is linear with time in every case, an induction period or swelling is observed in the very early stage.

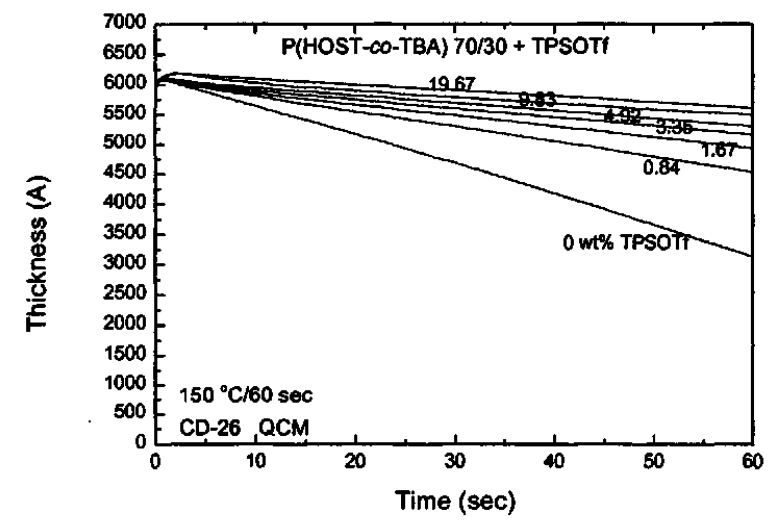

Fig. 9. Dissolution kinetics of $\mathrm{P}\left(\mathrm{HOST} \mathrm{T}_{0.7}-\mathrm{co}-\mathrm{TBA}_{0.3}\right)$ as a function of TPSOTf loading in CD-26.

Figure 10 presents dissolution rates in CD26 of the copolymer films baked at $150^{\circ} \mathrm{C}$ as a function of the TPSOTf loading. The rate becomes exponentially smaller with an increasing TPSOTf concentration, especially when the rate is high. Fig. 10 indicates that addition of a small amount of TPSOTf gives a larger inhibition effect and that a loading above $5 \mathrm{wt} \%$ does not slow down the dissolution rate any further, which suggests that the resist sensitivity could be increased without affecting the dissolution rate much by adding more TPSOTf, provided that the solubility and UV absorption characteristics allow. The dissolution inhibition effect of TPSOTf is larger when the dissolution rate is faster. Since the dissolution rate of the $60 / 40$ copolymer is already quite slow due to the high concentration of the TBA unit, addition of TPSOTf only slightly reduces its rate by $30 \%$ at most in CD-26. In a stronger developer, the TPSOTf loading effect could be more clearly observed with this composition. In the case of the fast dissolving 70/30 copolymer, the reduction of the dissolution rate by TPSOTf addition amounts to as much as $80 \%$. Furthermore, although addition of 1 wt $\%$ of TPSOTf to the 70/30 copolymer reduces its dissolution rate to the range of the pure 67.5/32.5 copolymer, the faster dissolving 70/30 copolymer cannot be made comparable with the $65 / 35$ copolymer in terms of the dissolution rate simply by increasing the TPSOTf loading. Thus, the copolymer composition should still be the primary variable in control of the dissolution rate while it can be adjusted to some extents by changing the loading of TPSOTf (or other PAGs).

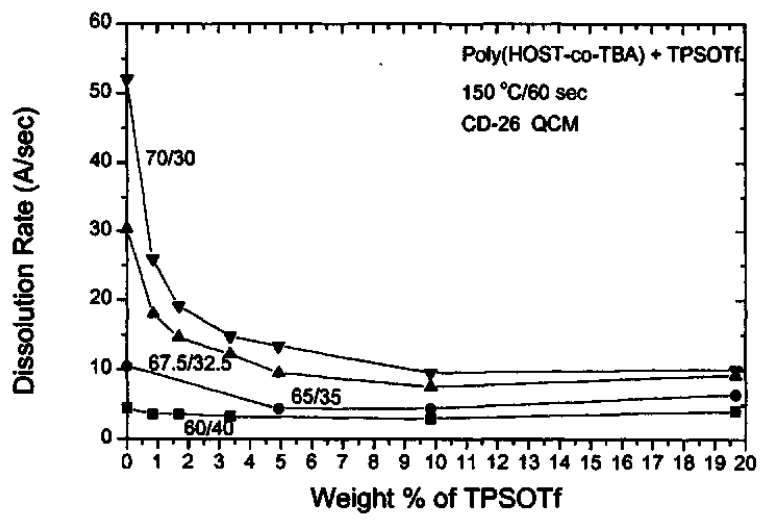

Fig. 10. Dissolution rates of $\mathrm{P}(\mathrm{HOST}-\mathrm{co}-\mathrm{TBA})$ as a function of composition and TPSOTf loading.

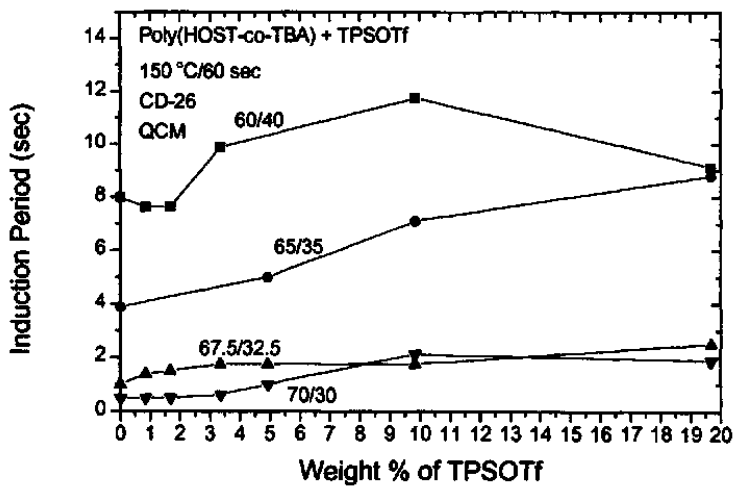

Fig. 11. Induction periods in dissolution of $\mathrm{P}$ (HOST-co-TBA)/TPSOTf films in CD-26.

As mentioned earlier, the copolymer film becomes slightly thicker upon contact with the developer presumably due to absorption of the 
liquid (swelling) and then begins to dissolve. The induction period is plotted in Figure 11 as a function of the TPSOTf loading for the copolymer films baked at $150{ }^{\circ} \mathrm{C}$ for $60 \mathrm{sec}$. The induction period is longer with a slower dissolving copolymer (higher TBA concentration) and at a higher TPSOTf loading, and can amount to as much as $12 \mathrm{sec}$.

\subsection{Deprotection and Dissolution Behavior of ESCAP (UVIIHS) Resist}

We have carefully studied the dissolution kinetics of the Shipley UVIIHS resist (prepared in house) and correlated its dissolution behavior with the degree of deprotection in the resist film. Figure 12 presents contrast (chemical and lithographic) curves of the UVIIHS ESCAP resist. The films were baked at $150^{\circ} \mathrm{C}$ for $60 \mathrm{sec}$, exposed through a cut-off filter to radiation from an OAI exposure station, and postbaked at $150{ }^{\circ} \mathrm{C}$ for $90 \mathrm{sec}$. The degree of acid-catalyzed deprotection (conversion of $t$-butyl ester to carboxylic acid) was monitored by following the thinning that occurs upon postexposure bake due to release of isobutene and also by following shrinkage of an IR absorption at $1150 \mathrm{~cm}^{-1}$ (or at $1369 \mathrm{~cm}^{-1}$ ). The film thickness was measured also after development with a $0.26 \mathrm{~N}$ TMAH aqueous solution (CD-26) for $60 \mathrm{sec}$. Fig. 12 suggests that the deprotection commences at 2-3 $\mathrm{mJ} / \mathrm{cm}^{2}$ and that the conversion reaches $\sim 100 \%$ at $\sim 15 \mathrm{~mJ} / \mathrm{cm}^{2}$. At the dose to clear $\left(\mathrm{E}_{0}=6 \mathrm{~mJ} / \mathrm{cm}^{2}\right)$, the degree of deprotection appears to be far below $100 \%$.

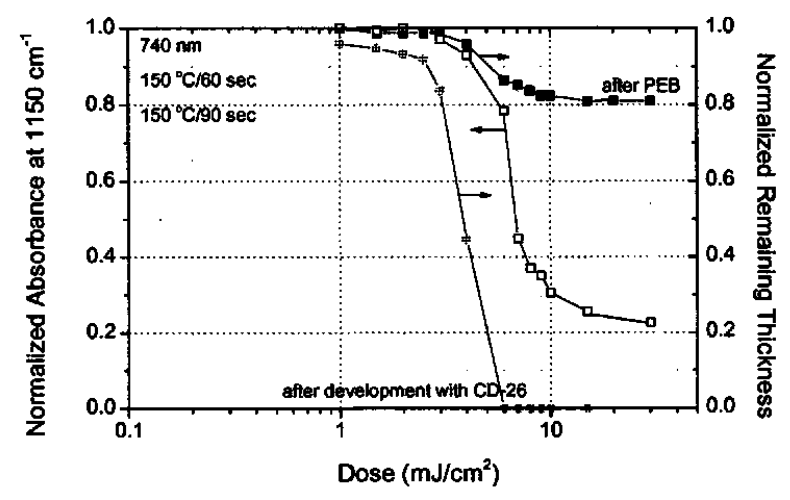

Fig. 12. Chemical and lithographic contrast curves of UVIIHS ESCAP.

To follow the deprotection reaction in the resist film more quantitatively and unequivocally, we have decided to utilize an inverse gate ${ }^{13} \mathrm{C}$ NMR technique in conjunction with the use of $\mathrm{Cr}(\mathrm{acac})_{3}$ as a relaxation agent. The resist films coated on fifteen 5 " silicon wafers were baked at $150^{\circ} \mathrm{C}$ for $60 \mathrm{sec}$, exposed through the same cutoff filter on the same exposure tool, postbaked at $150^{\circ} \mathrm{C}$ for $90 \mathrm{sec}$, scraped off with a razor blade, and dissolved in acetone- $\mathrm{d}_{6}(\sim 100 \mathrm{mg} / 500 \mathrm{mg})$ along with $\operatorname{Cr}(\mathrm{acac})_{3}$ (10 wt\% to the polymer) for each ${ }^{13}$ C NMR measurement (30,000 scans).

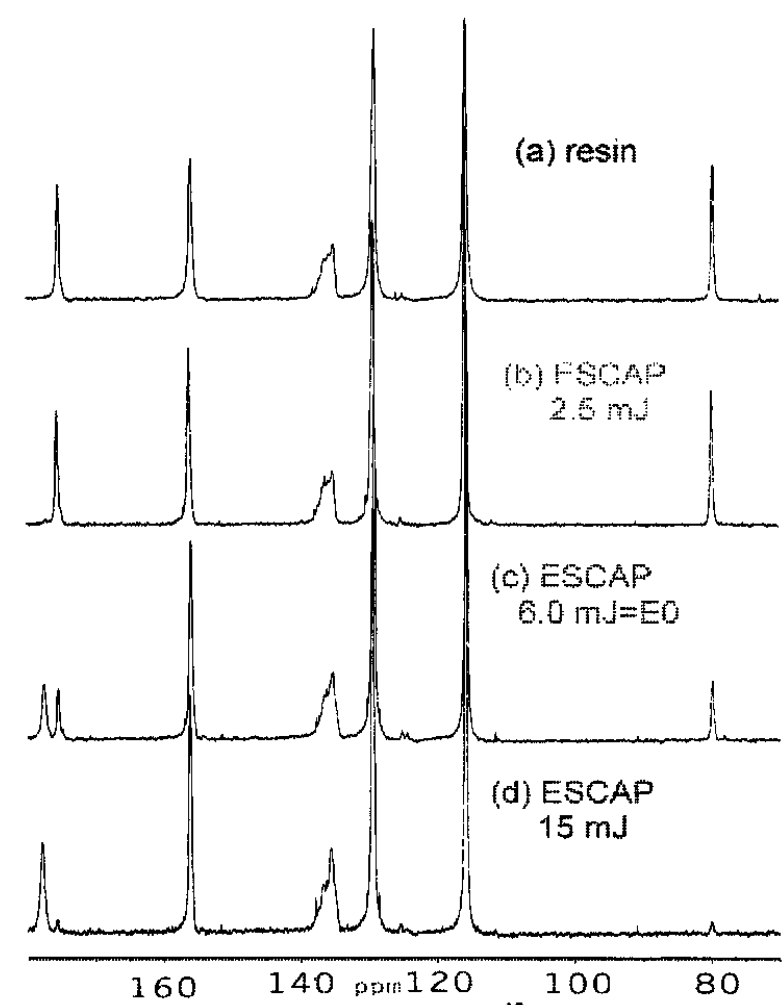

Fig. 13. 62.9 $\mathrm{MHz}$ inverse gate ${ }^{13} \mathrm{C}$ NMR spectra of the ESCAP resin (a) and resist exposed and postbaked at $150^{\circ} \mathrm{C}$.

Figure 13 exhibits $62.9 \mathrm{MHz}$ inverse gate ${ }^{13} \mathrm{C}$ NMR spectra of the ESCAP resin (a) and the resist exposed to critical doses selected from the contrast curves in Fig. 12. The deprotection reaction in the resist film can be quantitatively monitored by following shrinkage of the resonances at $\sim 80$ and $\sim 176 \mathrm{ppm}$ due to the quaternary and carbonyl carbons in the $t$-butyl ester group, respectively, and appearance of a carboxylic acid carbonyl resonance at $\sim 178 \mathrm{ppm}$. According to Fig. 12, significant deprotection and therefore dissolution begin at $\sim 2.5 \mathrm{~mJ} / \mathrm{cm}^{2}$, which we call a "threshold dose", $\mathrm{E}_{\mathrm{th}}$. At this dose, the conversion is only $5 \%$ (Fig. 13b). Above $E_{t h}$, the deprotection and dissolution are accelerated, reaching the full development at $6 \mathrm{~mJ} / \mathrm{cm}^{2}\left(\mathrm{E}_{0}\right)$. At $\mathrm{E}_{0}, 61 \%$ of the $t$-butyl ester is converted to carboxylic acid (Fig. 13c). Although the chemical contrast curves in Fig. 12 suggest that 
the deprotection reaction is completed at $\sim 15$ $\mathrm{mJ} / \mathrm{cm}^{2}$, the NMR analysis has indicated that the conversion is actually $\sim 95 \%$ at this dose. The degree of deprotection has been found to be still $\sim 95 \%$ at $50 \mathrm{~mJ} / \mathrm{cm}^{2}$ by the NMR technique. The deprotection reaction reaches a plateau at $\sim 95 \%$ conversion. When the resist film was postapplybaked at $130^{\circ} \mathrm{C}$ for $60 \mathrm{sec}$ and postexposure-baked at $140{ }^{\circ} \mathrm{C}$ for $90 \mathrm{sec}$, the $\mathrm{E}_{0}$ was $10 \mathrm{~mJ} / \mathrm{cm}^{2}(\mathrm{CD}$ 26) and the conversion at $\mathrm{E}_{0}$ was $69 \%$ according to our NMR analysis.

Thus, inverse gate ${ }^{13} \mathrm{C}$ NMR can provide valuable quantitative information regarding the degree of deprotection in the resist film. Moreover, the NMR technique is capable of offering finer details about the resist film including the residual casting solvent and side reactions. For example, the residual ethyl lactate remaining in the ESCAP resist film after baking at $150{ }^{\circ} \mathrm{C}$ for $60 \mathrm{sec}$ has been determined to be $0.3-0.4 \mathrm{wt} \%$ of the polymer by ${ }^{13} \mathrm{C}$ NMR.

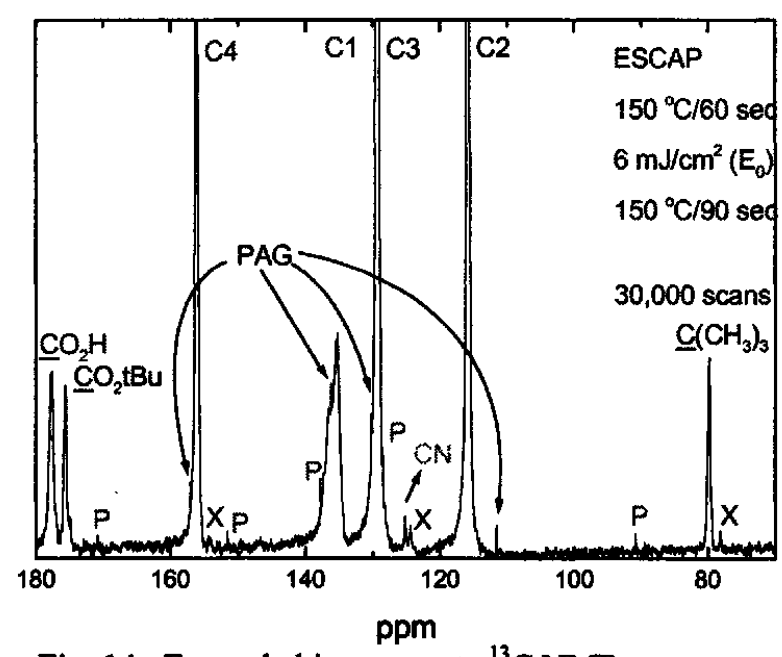

Fig. 14. Expanded inverse gate ${ }^{13} \mathrm{C}$ NMR spectrum of the ESCAP resist film exposed to $6 \mathrm{~mJ} / \mathrm{cm}^{2}$ and postbaked at $150^{\circ} \mathrm{C}$.

In Figure 14 is exhibited an expanded ${ }^{13} \mathrm{C}$ NMR spectrum of the UVIIHS ESCAP resist postapply-baked at $150^{\circ} \mathrm{C}$ for $60 \mathrm{sec}$, exposed to 6 $\mathrm{mJ} / \mathrm{cm}^{2}\left(\mathrm{E}_{0}\right)$, and postexposure-baked at $150^{\circ} \mathrm{C}$ for $90 \mathrm{sec}$ (Fig. 13c). The polymer was made by radical copolymerization with 2,2'-azobis(isobutyronitrile) and thus contains a $\mathrm{CN}$ end group, which is clearly observed at $\sim 126 \mathrm{ppm}$. The aromatic resonances of the PAG employed in the formulation are also clearly detected and the NMR integration of the unexposed resist film has given the PAG concentration which agrees very well with the gravimetric amount employed to formulate the resist. Furthermore, the photolysis products $(\mathrm{P})$ of the PAG are also nicely detected by this technique. In addition, a side product $(\mathrm{X})$ generated by $O$-alkylation, which is a $t$-butyl ether of phenol, has been shown to be present in the exposed/postbaked ESCAP resist film, which has been confirmed by comparison with an NMR spectrum of an authentic polymer. ${ }^{1} \mathrm{H}$ NMR could not provide such detailed information due to resonance overlap.

Figure 15 presents the degrees of the acid-catalyzed deprotection and $O$-alkylation in the ESCAP resist film as a function of the exposure dose as determined by the ${ }^{13} \mathrm{C}$ NMR technique. The bake conditions were $150{ }^{\circ} \mathrm{C} / 60$ $\sec$ and $150^{\circ} \mathrm{C} / 90 \mathrm{sec}$. The $t$-butyl ester groups is smoothly converted to carboxylic acid above $\sim 2$ $\mathrm{mJ} / \mathrm{cm}^{2}$, accompanied by concurrent $O$-alkylation to form a $t$-butyl ether. Apparently, the $t$-butyl carbocation generated by reaction of the $t$-butyl ester with photochemically-generated acid reacts (to a minor extent) with the phenolic $\mathrm{OH}$ group before it undergoes $\beta$-proton elimination and escapes out in the form of isobutene. The maximum concentration of the $t$-butyl ether built up in the resist film is only $2 \mathrm{~mol} \%$ and the $t$ butyl ether appears to undergo acid-catalyzed deprotection at higher doses because it is also acid-labile. $C$-alkylation was not observed within the detection limit. Lowering the bake temperatures to $130 / 140{ }^{\circ} \mathrm{C}$ did not affect the degree of the side reaction.

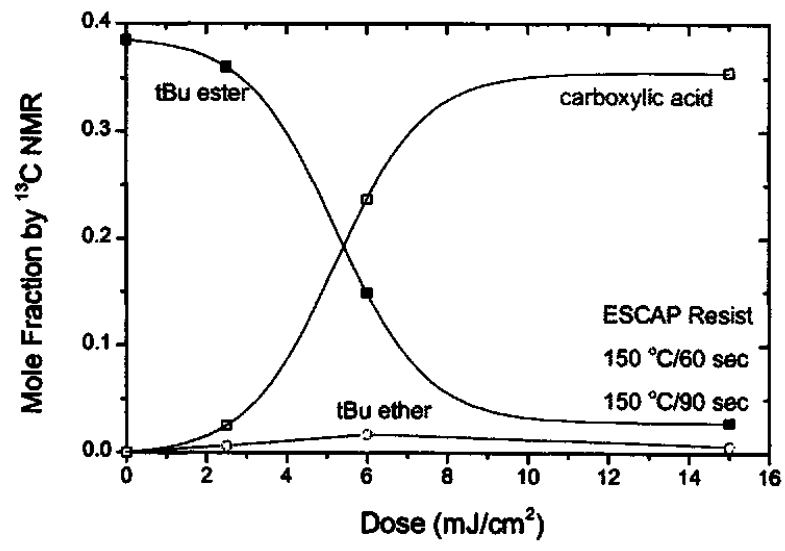

Fig. 15. Acid-catalyzed deprotection and $O$-alkylation in the ESCAP resist film as studied by ${ }^{13} \mathrm{C}$ NMR.

The dissolution rate of the UVIIHS ESCAP resist was measured in a $0.26 \mathrm{~N}$ TMAH developer (CD-26) using a QCM. The resist films cast on Au-coated quartz wafers were baked at $150^{\circ} \mathrm{C}$ for $60 \mathrm{sec}$, exposed to $254 \mathrm{~nm}$ radiation 
from the OAI exposure station, and postbaked at $150^{\circ} \mathrm{C}$ for $90 \mathrm{sec}$ prior to the QCM measurements. The dissolution kinetics of the resist films exposed lightly $\left(0-6 \mathrm{~mJ} / \mathrm{cm}^{2}\right)$ is presented in Figure 16 . The unexposed film is essentially insoluble in the developer for at least $200 \mathrm{sec}$. Below $\mathrm{E}_{\text {th }}(<2.5$ $\mathrm{mJ} / \mathrm{cm}^{2}$ ) the dissolution is minimal. At $E_{t h}$ the film surface begins to interact with the developer although the dissolution is still negligible because of a low conversion of only $5 \%$. When the exposure dose is increased slightly from $E_{t h}$ to 3-4 $\mathrm{mJ} / \mathrm{cm}^{2}$, the deprotection reaction is accelerated and a tremendous swing in the dissolution rate results. At the dose close to $E_{0}$, the initial dissolution rate is enormously high. The dramatic increase in the dissolution rate that occurs between 3 and $4 \mathrm{~mJ} / \mathrm{cm}^{2}$ is well detected by QCM. The resist develops to the substrate at $E_{0}$ in a couple of seconds while its development time is typically 60 sec. Interferometric measurement techniques often fail to follow such fast dissolution. Since the conversion is only $60 \%$ at $\mathrm{E}_{0}$, the dissolution kinetics study was extended to higher doses as shown in Figure 17. Above $\mathrm{E}_{0}$, the film dissolves away within $1 \mathrm{sec}$. Although the dissolution rate does not seem to change much above $E_{0}$, the induction period becomes shorter at higher doses, which probably reflects further deprotection reaction. As the NMR study indicates, the deprotection saturates at $95 \%$ at $\sim 15 \mathrm{~mJ} / \mathrm{cm}^{2}$. Thus, the dissolution behavior is unchanged finally above this dose $\left(20 \mathrm{~mJ} / \mathrm{cm}^{2}\right.$ in Fig. 17).

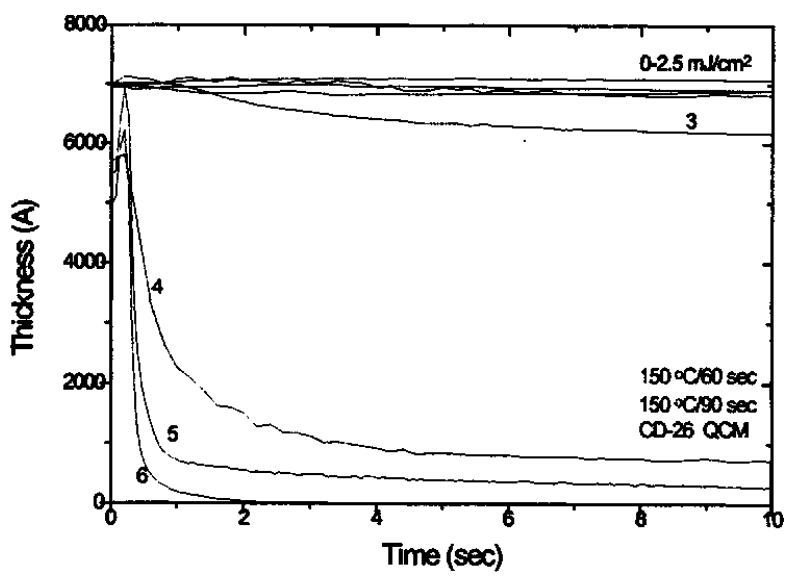

Fig. 16. Dissolution kinetics of UVIIHS ESCAP in CD-26 below $\mathrm{E}_{0}$ as measured by QCM.

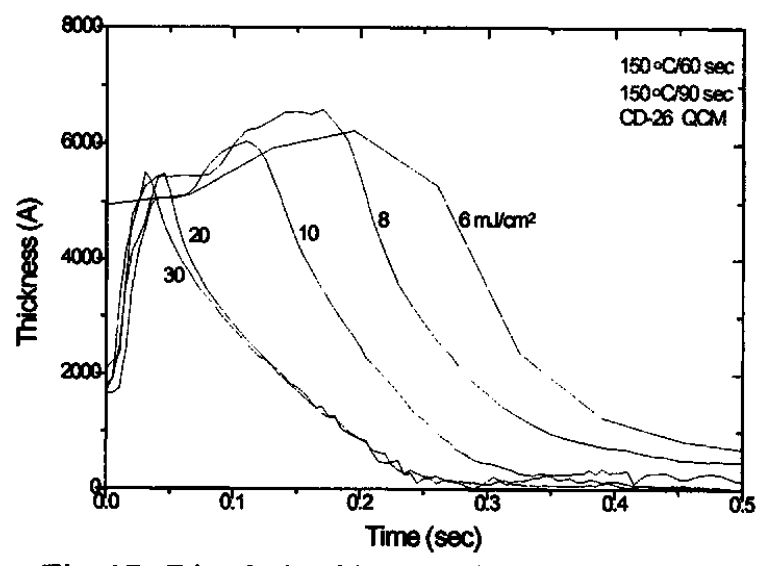

Fig. 17. Dissolution kinetics of UVIIHS ESCAP in CD-26 above $\mathrm{E}_{0}$ as measured by QCM.

In Figure 18 are presented the initial dissolution rates of the UVIIHS ESCAP resist determined from Figs. 16 and 17 and the concentration of carboxylic acid generated in the film as determined by ${ }^{13} \mathrm{C} N M R$ as a function of the exposure dose. The unexposed film has a dissolution rate of $2.2 \AA / \mathrm{sec}\left(\mathrm{R}_{\min }\right)$. When the carboxylic acid concentration in the resist film becomes greater than $2-3 \%$, the dissolution rate kicks off, reaching the maximum rate of $>20,000$ $\AA / \sec \left(R_{\max }\right)$ at \% carboxylic acid of $25 \%$. This drastic increase in the dissolution rate is due to conversion of the $t$-butyl ester to carboxylic acid, which provides much greater dissolution differentiation than a system that generates phenol. The developer selectivity of the resist is $\sim 15$, indicative of its high performance. The very large $R_{\max } / R_{\min }$ of $>10,000$ is the reason why the resist is capable of printing small contact holes cleanly with vertical wall profiles even when significantly underexposed [4].

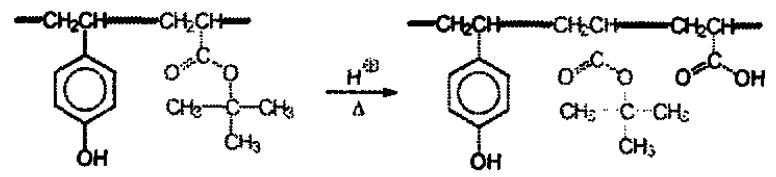




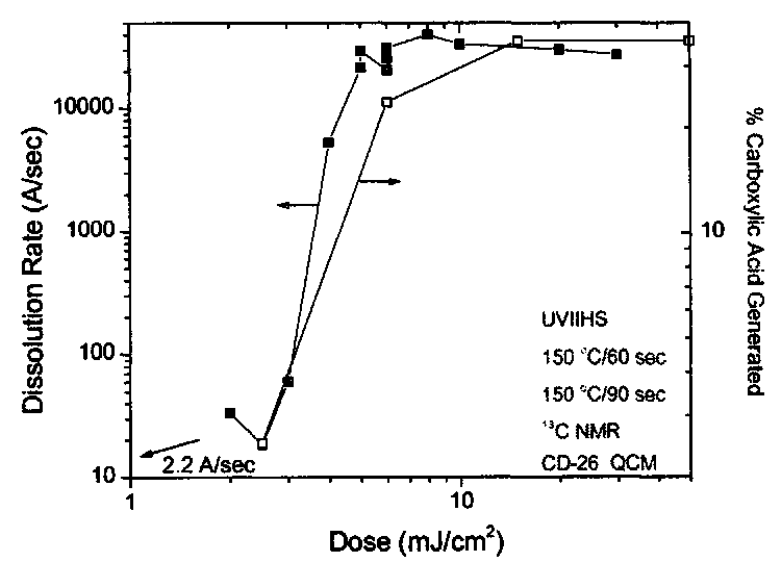

Fig. 18. Dissolution rates of and \% carboxylic acid generated in UVIIHS ESCAP as a function of exposure dose.

The ESCAP resin and resist films were also subjected to AFM analysis as shown in Figure 19. The ESCAP copolymer film baked at $150^{\circ} \mathrm{C}$ for 60 sec had a smooth surface with a mean roughness of $2 \AA$ and dipping the film briefly in CD-26 increased the roughness to $10 \AA$. The unexposed ESCAP resist films after bake at $150{ }^{\circ} \mathrm{C}$ and after brief dipping in CD-26 were very similar to the resin films in terms of the mean roughness. When the resist film was lightly exposed, the mean roughness increased to ca. $20 \AA$ after short dip in the developer but postexposure bake of the exposed film did not cause any surface roughness.

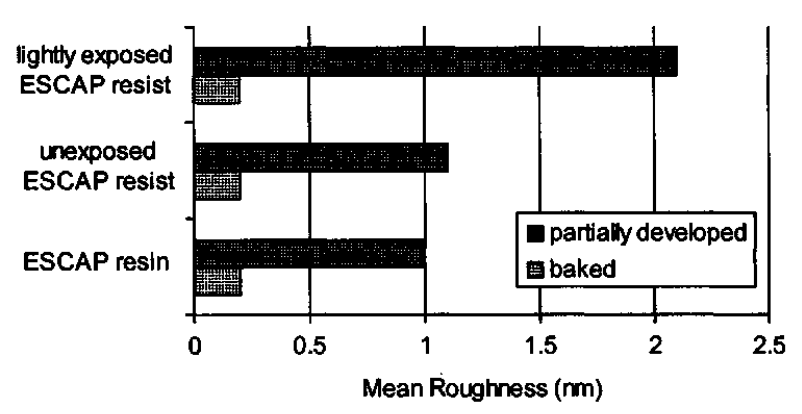

Fig. 19. Mean roughness of ESCAP resin and resist films after $150^{\circ} \mathrm{C}$ bake and short dip in CD-26 as measured by AFM.

In an attempt to further understand the dissolution behavior of the ESCAP resist film in aqueous base, we have prepared authentic terpolymers of HOST, TBA, and acrylic acid (AA) by treating $\mathrm{P}\left(\mathrm{HOST}_{0.615}-c o-\mathrm{TBA}_{0.385}\right)$ with hydrochloric acid in dioxane. The compositions of the terpolymers were determined by inverse gate ${ }^{13} \mathrm{C}$ NMR with $\mathrm{Cr}(\mathrm{acac})_{3}$ in acetone- $\mathrm{d}_{6}$. Figure 20 presents dissolution kinetics curves, obtained by using QCM in CD-26, of the authentic P(HOSTTBA-AA) films baked at $150^{\circ} \mathrm{C}$ for $60 \mathrm{sec}$. The dissolution kinetics of the authentic terpolymers is very much linear with time, which is in sharp contrast with the dissolution behavior of the exposed/postbaked resist films. The nonlinear dissolution kinetics, fast dissolution followed by slow dissolution, of the exposed resist films may be ascribed at least in part to the UV absorption of the resist film. The UVIIHS ESCAP resist is highly transparent at $248 \mathrm{~nm}$ with an optical density of $0.24 / \mu \mathrm{m}$. However, the transmission of a $1-\mu \mathrm{m}$-thick film is $57 \%$ and thus the exposure energies could significantly vary along the thickness of the film.

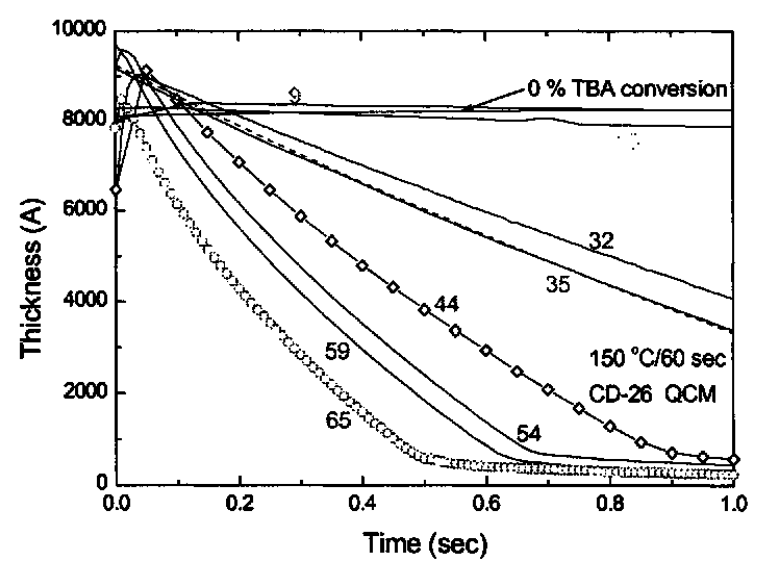

Fig. 20. Dissolution kinetics of authentic P(HOSTTBA-AA) films baked at $150^{\circ} \mathrm{C}$ (in CD-26).

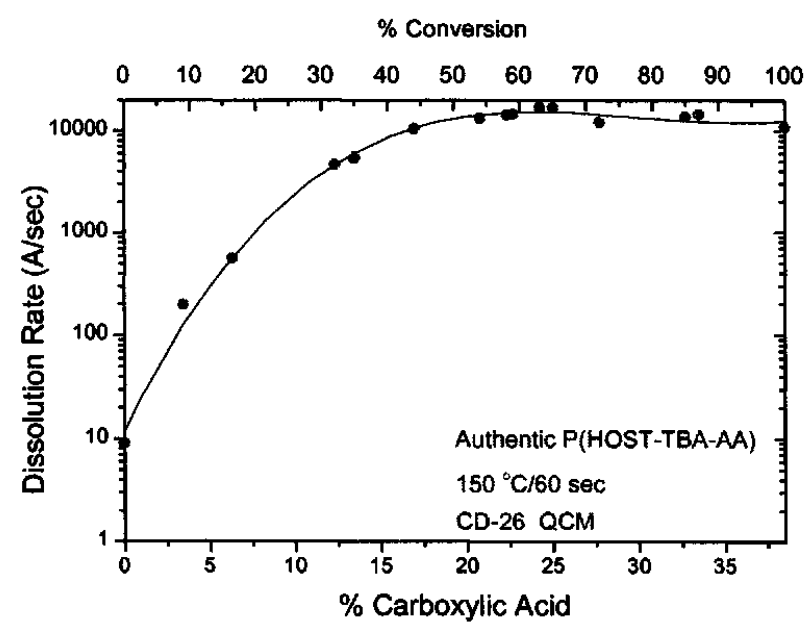

Fig. 21. Dissolution rates of authentic P(HOST-TBAAA) films baked at $150^{\circ} \mathrm{C}$ in CD-26 as a function of $\%$ carboxylic acid. 
In Figure 21 are plotted the dissolution rates in CD-26 of the authentic terpolymers of HOST, TBA, and AA as a function of $\%$ carboxylic acid (AA). Generation of a small amount of carboxylic acid induces a profound increase in the dissolution rate and the dissolution rate appears to reach the maximum value at about $60 \%$ conversion ( $25 \%$ carboxylic acid), which are in total accord with our studies on the exposed resist films.

\section{Summary}

The dissolution kinetics of PHOST and P(HOST-co-TBA) films and the influence of PAG (especially onium salts) on the dissolution behavior of the phenolic resins have been investigated using QCM. Interaction between PAGs and a phenolic functionality has been studied by ${ }^{13} \mathrm{C}$ NMR and IR, which has been correlated with the dissolution inhibition effect. Detailed dissolution kinetics studies have been carried out on the UVIIHS ESCAP resist, which has been made possible by the use of QCM. The dissolution behavior of the UVIIHS ESCAP resist has been correlated with the degree of deprotection as determined by inverse gate ${ }^{13} \mathrm{C}$ NMR as a function of the exposure dose and also with use of the authentic partiallydeprotected polymers.

\section{Acknowledgments}

The authors thank Melissa Bower for her thermal and GPC analyses, Mark Sherwood for his NMR maintenance, and Tony Logan and Jane Frommer for their AFM work.

\section{References}

1. W. D. Hinsberg, C. G. Willson, and K. K. Kanazawa, J. Electrochem. Soc., 133 (1986) 1448.

2. H. Ito, Proc. SPIE, 920 (1988) 33.

3. H. Ito, E. Flores, and A. F. Renaldo, $J$. Electrochem. Soc., 135 (1988) 2328.

4. W. Conley, G. Breyta, B. Brunsvold, R. DiPietro, D. Hofer, S. Holmes, H. Ito, R. Nunes, G. Fichtl, P. Hagerty, and J. Thackeray, Proc. SPIE, 2724 (1996) 34.

5. H. Ito, G. Breyta, D. Hofer, R. Sooriyakumaran, K. Petrillo, and D. Seeger, $J$. Photopolym. Sci. Technol., 7 (1994) 433.

6. G. G. Barclay, C. J. Hawker, H. Ito, A. Orellana, P. R. L. Malenfant, and R. F. Sinta, Proc. SPIE, 2724 (1996) 249.

7. C. J. Hawker, G. G. Barclay, A. Orellana, and J. Dao, Macromolecules, 29 (1996) 5245.

8. H. Ito and E. Flores, J. Electrochem. Soc., 135 (1988) 2322.

9. R. A. DiePietro, G. Breyta, and D. J. Dawson, Abstracts ACS, 207 (1994) 287(ORGNMY955); G. Breyta, D. J. Dawson, R. A. DiPietro, and H. Ito, IBM Technical Disclosure Bulletin, 38 (1995) 509. 